\title{
LANGUAGE EDUCATION AND BAHAMIAN STUDENTS' COMPOSITIONS
}

By Michelle Veronica Bain

https://doi.org/10.15362/ijbs.v13i0.57

\section{ABSTRACT}

The teaching of Standard English (SE) composition in the Bahamas is not without its challenges in the context of the sociolinguistic situation. Many Bahamian students' Standard English compositions exhibit "interference" from vernacular Bahamian, either Bahamian English Creole or Bahamian Dialect. In this study, I attempt to clarify issues of creole/dialect interference in the Standard English writing of college-based English compositions providing some linguistic explanations for many of the so-called "errors of grammar" in the compositions of Bahamian students.

In order to fulfill the linguistic needs of all Bahamian students and to ensure greater success in Standard English performance in the Bahamian public schools, I propose that language educators consider TESD--Teaching English as a Second or Other Dialect-- for the Bahamian context. However, TESD would dictate a re-examination of our present language education methodologies and our linguistic assumptions about the acquisition of Standard English conventions by the Bahamian school age population. Moreover, I attempt to answer two major questions about the frequency and distribution patterns of the "errors of grammar" and non-standard features recurrent in students' expository compositions. I also explore possible linguistic factors that can account for such distribution. Furthermore, by analyzing specific samples of college-based compositions from The College of the Bahamas, my preliminary results indicate considerable levels of linguistic interference from vernacular Bahamian, especially within the SE lexicon. 
What are we really accomplishing in our English language clasrooms in The Bahamas-- and what might language educators do to better fulfill the needs of their students? After several years of languishing on the shelf, this composition analysis based upon my Master's thesis, still seems applicable to College English pedagogy at The College of The Bahamas (C.O.B.), and to language education policy in The Bahamas, as "errors of grammar" and non-standard features remain a constant variable in college-based English compositions.

I believe that English Language (EL) teachers who are interested in helping their students achieve their highest communicative competence in a Standard English (SE) variety, particularly in composing SE texts, may also be interested in delivering excellent instruction to our student populations. At times, we are forced to stop and probe the nature of our instruction. Unfortunately, many composition studies have limited their scope to investigating the teaching of English as a first language when it can be observed that English, in classrooms across the world, is taught as a first, second or foreign language, and even as a second dialect, as the sociolinguistic contexts dictate. In this composition study, I summarize my research findings on "errors of grammar" and nonstandard features in college-based compositions; the preliminary results provide some insightful perspectives about the need for more effective and innovative teaching methodologies. I also hope to ignite interest in second language/second dialect methodologies, in the vein of additive language competencies.

I first became interested in critical language teaching/learning issues during my formative studies in English Language and Linguistics in the 1980's at C.O.B. Since then, I had become even more concerned about the effectiveness of EL teaching in the Bahamian public institutions, and I had begun to investigate the situation by collecting data from students' college English compositions and language teachers. I believe that in the sociolinguistic context of the Bahamas, as in other Caribbean territories, many students' SE compositions will exhibit linguistic interference or pragmalinguistic transfer from their local Bahamian vernaculars, namely, Bahamian English Creole (BEC) and Bahamian Dialect (BD). This paper unfolds as an informative discussion about the major errors and non-standard features that surfaced in my compositional analysis during research for my thesis, and the attendant pedagogical ramifications (Major, 1993).

\section{STATEMENT OF THE PROBLEM}

Which non-standard features are recurrent in students' expository compositions written at C.O.B.? What factors seem to account for the distribution of these non-standard features? My study attempts to explicate some of the pertinent issues of creole and dialect interference in SE expository compositions of Bahamian students, and it draws upon linguistic insight gleaned from the work of several Bahamianists. Based upon a key socio-historical investigation of the settlement patterns of the Bahamian islands, Lawlor, a prominent Bahamianist, has postulated that a non-standard dialect of Bahamian English is generally spoken in the northeastern islands, while a Bahamian English Creole is generally spoken in the southeastern islands, with New Providence demarcating a linguistic crossroad between the two regions 
(1988: 13). Lawlor's study elucidates some significant socio-historical factors that are implicated in the genesis of Afro-Bahamian language varieties spoken throughout The Bahamas, in the eighteenth century; "more specifically, the question of whether the linguistic system of the Bahamian slave society in the eighteenth century was genetically and typologically related to an English grammar or to an African grammar" (1). In addition, based upon their seminal work on Bahamian English, Holm and Shilling (1982), imply a creole ancestry for basilectal Bahamian, with its attendant range of language variation and non-standard features. Furthermore, Holm and Shilling (1982: x) summarize what many Bahamian teachers have acknowledged about their students' performance in the English language classroom:

....relatively few students ever achieve total mastery of the Standard English verbal system; the mesolect, in fact, is a maze of strategies attempting to reconcile the irreconcilable differences between the verbal systems of the basilect and the acrolect.

Such linguistic factors, attested by these Bahamianists for vernacular Bahamian, would significantly affect English Language teaching and learning in the Bahamas.

On beginning formal education, many Bahamian students who speak nonstandard Bahamian continue to be "misunderstood" and not achieve their highest potential. With Standard English proficiency at the center of the educational enterprise with political ramifications, it is deemed a necessity for the efficient administration of any modern economy with international relations. However, when SE is both the medium and target of education in a country such as the Bahamas, language difficulties are inevitable for both teachers and students, and the first language of the majority of the schoolentering population will continue to exert influence on SE learning. I propose that unless many of the challenges facing language education be addressed with an understanding of the sociolinguistic history of the Bahamas, the lack of full proficiency in Standard English by a greater majority of Bahamians will continue to undermine language education efforts. The underlying assumption being posited here is that SE may be neither native nor foreign to a large majority of Bahamians, but it is acquired later, primarily through formal language education, as a second dialect/language.

Even though my study provides some insight into the interrelationship of linguistic factors with educational policy in the Bahamian contexts, two major limitations should be noted. First, the current sociolinguistic situation and the language education orientation in the Bahamas do not impede all Bahamian students in their educational pursuits as many of them do graduate from high schools and from C.O.B. with some competence in SE. This study, however, delineates some linguistic reasons underlying the poor and inadequate EL performance of the large majority of Bahamian students who "struggle" with SE proficiency throughout their academic careers. Secondly, this study does not discuss process-oriented compositions because my original analysis was limited to written texts composed under strict examinations conditions without any chances of face-to-face conferences with the student writers in order to obtain some insights into their production process. I had selected writing as a focus of college students' performance because I readily obtained written pieces from my English department, and I had linguistic insight that enabled 
me to explicate some of the major differences between SE and Non-standard Bahamian and composition is also an integral instrument used to measure students' SE proficiency. Thus, proficiency in other language arts skills were beyond the scope of the study.

\section{REVIEW OF LITERATURE}

In ES/FL (English as a Second or Foreign Language) circles, language interference may be defined as "the negative effect of new learning on the performance of previously learned behavior-- prior language acquisition-- with which it is inconsistent" (Selinker, 1992: 33-34). Thus, linguistic competence in second language/dialect acquisition may be impeded because of interference from the linguistic rules of the first (native) language. Such interference in the Bahamian complex may cause student-speakers to generate unstable and undesirable structures when they attempt to use Standard Bahamian, the target language. Linguistic transfer, on the other hand, may refer to "the incorporation of linguistic features from one language to the other" according to Selinker (1992: 33-34). In the Bahamian context again, student-speakers "carry over" vernacular Bahamian features of their first language when they attempt to formulate structures in the target. However, I used both terms interchangeably, with interference serving as the generic form describing the various possibilities of "error production." "Errors" in this paper can be defined as the linguistic structures that do not approximate standard conventions of writing, but that do reflect the learner's level of competence in a target language. Actually, Crystal's (1999: 125) definition of "error analysis" coincides exactly with my sentiments advocated in this study:

In language teaching and learning, error analysis is a technique for identifying, classifying and systematically interpreting the unacceptable forms produced by someone learning a foreign language, using any of of the principles and procedures provided by linguistics. Errors are assumed to reflect, in a systematic way, the level of competence achieved by a learner; they are contrasted with "mistakes," which are performance limitations that a learner would be able to correct.

(Italicized portions are my emphasis).

Linguists, like myself, who are also writing instructors, have generally identified three distinct syntactic categories of dialectal interference that seem rooted in students' knowledge of a non-standard grammar: (1) avoidance strategies; (2) negative L1 transfer; and (3) non-ruled based features. According to Gray (1975: 16) these three major categories attempt to identify some of the causes of SE writing problems in non-standard dialect-speaking students' compositions. Avoidance Strategies: Indeed, students often avoid particular syntactic constructions necessary in expressing certain nuances of meaning and complex relationships, such as sentential subordination. Familiar language patterns from the native language are not replaced by equivalent SE forms because these are unknown. The necessary SE structures may be totally circumvented. Even though features in this first category may go unnoticed as errors, the outcome is that students' writing suffers from a lack of depth, development, or maturity of thought and analysis. Such underachievement may then push a student into an "unproductive corner," according to Gray (1975:17). But most significantly, Gray (1975: 17) postulates that students' avoidance of some SE rules necessitates an informative pedagogical approach 
that may approximate foreign language teaching techniques because some SE structures are entirely foreign to many students. Negative L1 Transfer: Students' writing may also exhibit overt dialect-influenced structures, which are significantly visible to SE readers because of their markedness. These features may include systematic occurrences resonant with dialect features, but are unacceptable based upon standard writing conventions. Included in this category are uses of relativizers, inflectional suffixes, and verbal forms. Many student writers often fail to recognize inappropriateness of use of certain vernacular structures when composing SE texts. Moreover, according to Gray (1975), students may regard features in this second category as acceptable in their SE writing because of the "security blanket" of their linguistic intuitions, and their judgments and perceptions of "school English." So in order to produce the required SE structures, students have to reject or suppress native tendencies of long standing use, that seem more salient, natural and appropriate. Writing teachers can often help these vernacular-speaking students, as Gray (1975) suggests, by following a comparative teaching technique, wherein equivalent forms from the two language systems are compared and the rules of writing versus the rules of speech are extrapolated. The pedagogy advocated here must be systematic and comprehensive in order for the students to obtain a clear perspective of standard usage rules while maintaining the integrity and covert value of their native dialect. Non-rule Based Features: These written forms are not necessarily present in the native dialect or spoken interaction of the students, and thus, are unacceptable in both language systems. Hypercorrection may explain some of these occurrences and in the Discussion of Results sections, these are attributed to other factors without further discussion.

\section{CONCEPTUAL FRAMEWORK}

The theoretical framework for the study comes from bodies of literature on the teaching of SE composition at the college level, TES/FL methodology, language acquisition studies, and studies pertaining to the emergence of Creoles as independent language systems. However, this compositional error analysis follows Winer's (1992) model of examining compositions written in a Caribbean territory with its own creole and non-standard dialect varieties. Like Winer, notably, a number of Caribbean educators have already proposed such methodological changes in language education contexts based upon the language contact situation in the region and based upon the volumes of data depicting systematic linguistic differences between the standard European languages and Caribbean creole languages co-existing in the Caribbean territories (Winford 1976, Craig 1980, Carrington 1983, Winer 1982 \& 1992). Furthermore, the National task force on education: final report, a classic comprehensive review of the Bahamian education system, recommended in relation to language education reform, that second language methodologies be considered as alternative means for achieving greater SE proficiency (1994: 44-46 ). In its discussion on the need for teacher re-training and the development of ESL/D curricula and indigenous teaching materials, the following sentiment was expressed as a crucial recommendation:

The appropriate response to children whose exposure to the formal language is limited to school may require the development of an ESD curriculum designed to meet the needs of speakers of Bahamian dialect. The development of this curriculum must also be accompa- 
nied by the training of teachers to teach ESD (English as a second dialect).

In support of language education reform, the Caribbean linguists and language educators mentioned in my study, have also posited that a creole language that adopts its lexical base (vocabulary) from a European language may not be perceived as a distinct system of communication. This perception, in many cases, may have led language educators in the Caribbean, the Bahamas included, to conclude that their students at various levels of English language education who exhibit poor language performance are either lackadaisical or careless when they do not consistently produce SE structures in their speech or in writing. However, linguistically, the syntactic systems of SE and non-standard Bahamian are markedly distinct, especially in the tense-moodaspect (TMA) domains. Thus, it should not be surprising that the SE syntax, allied with the maze of SE writing conventions, poses some linguistic difficulties for English-Creole speaking or non-standard dialect-speaking students in their efforts to compose texts. Moreover, in the Bahamas, such difficulties that I mention here are being exacerbated by the lack of overt contrastive teaching methodologies in the language education arena. A contrastive methodology would delineate and illuminate linguistic boundaries between different language systems. Winer (1982: 65-66) confirms this too for Trinidad and Tobago in her study of the errors cropping up in the written English compositions of Trinidadian English Creole speakers. Moreover, Winer (1992) posits that the overlap that is evident between a Creole and its lexically-related European "make it intrinsically difficult to distinguish between the two languages in many areas" (p. 1033). Also, according to Winer (1992), the teaching of English as a second dialect to speakers of non-standard dialects and language varieties is based upon the principle of additive linguistic competence in the target language in the learner's repertoire, rather than replacive competence. She affirms that the major objective of TESD instruction is to equip the learners with sufficient productive and functional command of some variety of the standard language, without attempting to eradicate their first (native) language. Winer (1992) also states that speakers of non-standard varieties of English have been "disadvantaged" in formal L1 school situations:

Speakers of these varieties have been and often still are assessed at school as deficient in verbal and cognitive skills, as deaf, as learningdisabled, and as educationally or psychologically disturbed, whereas the significant differences lie in a use of language with which their teachers may be unfamiliar and for which they have not been prepared (p. 1033).

The TESD approach is grounded on the linguistic premise that language variation and language differences are normal in any speech community; therefore, its techniques and strategies are "often contrastive, examining the grammar and vocabulary of different varieties, emphasizing variation and situational appropriateness in language, and using culturally and linguistically appropriate materials" (Winer 1992: 1034).

Furthermore, English as a Second Dialect (ESD) students would differ from English as a Second Language (ESL) students in levels of comprehensibility of the target language and in the frequency and distribution of "errors of grammar." These differences obtain because ESD students generally seem to pos- 
sess high levels of comprehension and in some cases reasonable production of SE structures because "similarities and overlaps yield positive progress in the beginning," but ESD students become stuck or "fossilized" in areas of the target language involving marked differences between the language varieties in contact. These core differences are especially evident in the morpho-syntactic and prosodic linguistic systems of Standard English and non-standard Caribbean Creoles, for instance.

\section{METHODOLOGY}

In this project, I followed a quantitative methodology by using student-compositions as my major sources of data collection. Initially, I collected approximately 300 compositions written under examinations conditions at C.O.B. But ultimately, I analyzed only 3 types of compositions for the feature analysis: approximately 75 Placement Entrance Compositions (PECs) from secondary students-- students attempting to matriculate into C.O.B.; and approximately 50 Final Examination Compositions (FECs) from ENG 017 and ENG 119 students-- students who were already registered at C.O.B. I selected the final composition corpus randomly and based upon the legibility of students' handwriting.

The English Department had designed the PEC segment as part of C.O.B.'s entrance exam to assess students' proficiency in SE exposition. The PECs were included in the original composition analysis in order to compare pre-college performance with college performance. The FECs were intended to assess students' written competence in SE after a semester of English composition instruction. It should be noted that ENG 017: Intermediate English II, is a college preparatory course, whereas ENG 119: College English Skills I, is a college-level English course. These two types- ENG 017 and ENG 119- afforded the researcher several advantages which seemed to outweigh any limitations. First, there was the authenticity of the test-taking situation with no room for intellectual dishonesty; and second, there was equal opportunity for the writers concerned, as students were afforded the same chance for objectivity, self-expression and exploration of a composition topic within the same time frame and scope. Also, access to examination compositions appeared less problematic than procedures involving unsupervised writing.

In analyzing the composition samples, I used modified parameters of error analysis developed by others, like Winer (1992). I noticed that the contexts of the frequency and distribution were the critical factors in determining types of errors and non-standard features. I coded the scripts in the composition sample and keyed them into a computer processing system; then I analyzed the compositions for errors and non-standard features. The well-formed sentence was the fundamental unit of analysis. According to Winer (1982: 104-105), "If a sentence satisfied the grammatical, lexical, contextual, and discourse conditions.... it was considered correct." If I deemed a sentence in the composition corpus unacceptable because it violated standard conventions, the problematic features were identified and classified according to three major categories: morphology, syntax, and lexicon. I recorded specific information about each "error"-- location in the script, context and type-- on a computerized masterscoring sheet. After computer processing, I recorded the results from each group of student writers on a separate master-scoring sheet that was designed to display the total number of errors, types of errors, error attribution and the overall percentages of frequency and distribution. Most significantly, I focused 
on isolating and categorizing all non-standard features and errors appearing in the student corpus. An "error" was categorized as morphological if it concerned deletion, addition or supply of a single inflectional morpheme (Winer, 1982: 110). Some examples follow:

*The Bahamas was onced viewed by tourist as a paradise. (once, tourists)

*There are no provision or definite solution to these problem. (provisions, solutions, problems)

An "error" was classified as syntactic if it entailed some global sentence structure correction such as the addition or deletion of a function or function word, or a change in word order. Some examples are:

*Whatever they see the people of the soap opera do, they will do. (on/in)

*So one must always keep their financial means in mind when they are planning to go on a vacation. (one's, one)

*We must show our kids the right way, they are our future most of what a child sees done, he will do, not mostly what we say.

*We have people what go to school abroad. (who)

An "error" was classified as lexical if another lexical item could replace it, or if the supply, addition or substitution of a derivational affix, etcetera, corrected it.

*It states that fumagating cars should not be on the road. (smoking)

* Repatriation of illegal immigration is a necessity. (immigrants)

*The hospital is one of the most highest area where we need to have more control of when it come to health resistant. (resistance)

In cases where the errors were not attributable strictly to one feature category, categories were combined. For example, if an error required both morphological and syntactical correction, it was classified as morpho-syntactic.

*Drug addiction is slowly broken down the society. (breaking)

*The high crime rate has even began to effect the tourism industry. (begun)

*The size of the hospital wards should increase. (should be increased)

Furthermore, I also separated Creole-influenced features from genuine SE errors. In this light, I classified a non-standard feature as Creole-induced if its occurrence could be linked to and explained by the creole grammar. (See Major, 1993: 21-52 for specific descriptions of Bahamian Creole features). A Creole-induced error may correspond exactly to some structure or pattern in the vernacular language (L1) and may result in incorrect (negative) transfer or 
linguistic interference in the learner's attempt to use the target standard language. The following are examples of errors coded as creole-influenced.

*These personal sacrifices may include giving up something what they really need or want in order to help them with something else. (that)

*Most students have to scrap and save. (economize)

*Attempt Murder usually be done when a person go to rob another person. (is, goes)

*There are too many who resigning and seeking a more easier job. (are resigning, are seeking, much easier)

On the other hand, I labeled a feature as English-influenced if it revealed the writer's inadequate mastery of SE structure, or some intrinsic, perceived difficulty with SE patterns.

*Students are compelled to continued. (continue)

*Difficulties would just prepared them for the future. (would have prepared)

Finally, most errors that were attributed to the English \& Creole category depicted some inappropriate use of well-formed English words and phrases, resulting in structures that were neither correct Creole nor correct English. Some examples appear below:

*Schools does not end after high school.

*The majority of student find themselves in gangs.

${ }^{*}$ Carbon dioxide would not consum and we would die.

\section{DISCUSSION OF RESULTS}

The discussion focuses on a linguistic analysis of the college-based writing; all the sentential examples that are included, have been recorded verbatim from the PECs and FECs samples and have been numbered according to their original sequence in the composition corpus. The asterisk denotes a non-conventional sentence structure.

The following tables summarize some of the data results from composition samples. I calculated the frequencies of the error categories and the types of errors in Tables 2-10 by dividing the number of error occurrences in question by the total number of running words in each sample as depicted by Table 1 below. The frequencies facilitated the comparison and contrast of student performance and error distribution based upon the parameters established in the original design. 
Table 1: Totals of error/word count by composition sample type

\begin{tabular}{c|c|c|c|c|c}
\hline $\begin{array}{c}\text { Composition } \\
\text { Types }\end{array}$ & $\begin{array}{c}\text { Number of } \\
\text { Comps. in } \\
\text { Sample }\end{array}$ & $\begin{array}{c}\text { Total } \\
\text { Number } \\
\text { of Running } \\
\text { Words }\end{array}$ & $\begin{array}{c}\text { Average } \\
\text { Length } \\
\text { of Comps. } \\
\text { In Words }\end{array}$ & $\begin{array}{c}\text { Total } \\
\text { Number } \\
\text { of } \\
\text { Errors }\end{array}$ & $\begin{array}{c}\text { Average } \\
\text { Number } \\
\text { of Errors } \\
\text { per Paper }\end{array}$ \\
\hline PECs & 75 & 23,876 & 318 & 884 & 27 \\
\hline FECs-017 & 25 & 9,240 & 370 & 324 & 28 \\
\hline FECs-119 & 25 & 10,946 & 437 & 290 & 37 \\
\hline
\end{tabular}

FECs: The Final Examination Compositions-ENG 017 and ENG 119: The final examinations corpus consisted of 50 randomly selected composition-25 from ENG 017 batch and 25 from ENG 119. These FECs had been written on a variety of assigned topics composed under final examinations settings at C.O.B. in December, 1992. FECs-ENG 017: ENG 017 samples averaged 370 words (see Table 1) and explored several expository topics.

Table 2: FECs-017 error distribution by categories

\begin{tabular}{c|c|c}
\hline Error Categories & Number of Errors & \% of Total Errors \\
\hline Lexicon & 137 & 42 \\
\hline Morphology \& Syntax & 80 & 25 \\
\hline Syntax & 64 & 20 \\
\hline Morphology & 41 & 13 \\
\hline Morphology \& Lexicon & 2 & 100 \\
\hline Totals & 324 & - \\
\hline
\end{tabular}

The total number of errors within the ENG 017 sample was 324 (see Table 2). Lexicon accounted for 137 (42\%) errors; morphology and syntax accounted for 80 (25\%) errors; syntax accounted for 64 (20\%) errors; 41 (13\%) errors were morphological, and 2 were attributed to morphology and lexicon. Furthermore, as depicted by Table 3 below, the greatest number of errors in the ENG 017 sample was attributed to the English and Creole category, totaling 169 (52\%). The English category accounted for 133 (41\%) errors, while the Creole category accounted for $6(2 \%)$ errors, and 16 were attributed to other factors.

Table 3: FECs-017 error attribution

\begin{tabular}{ccc}
\hline Error Attribution & Number of Errors & \% of Total Errors \\
\hline English & 133 & 41 \\
\hline English \& Creole & 169 & 52 \\
\hline Creole & 6 & 2 \\
\hline Other & 16 & 5 \\
\hline Totals & 324 & 100 \\
\hline
\end{tabular}


FECs-ENG 119: The ENG 119 composition samples averaged 437 words (see Table 1) and also explored several expository topics.

Table 4: FECs-119 Error Distribution By Categories

\begin{tabular}{ccc}
\hline Error Categories & Number of Errors & \% of Total Errors \\
\hline Lexicon & 109 & 38 \\
\hline Syntax & 91 & 31 \\
\hline Morphology \& Syntax & 62 & 21 \\
\hline Morphology & 27 & 9 \\
\hline Syntax \& Lexicon & 1 & - \\
\hline Totals & 290 & 99
\end{tabular}

The total number of errors within the ENG 119 sample was 290 (see Table 4). Lexicon accounted for 109 (38\%) errors; syntax accounted for 91 (31\%) errors; morphology and syntax accounted for 62 (21\%) errors; 27 (9\%) errors were morphological; and 1 error was attributed to syntax and lexicon.

Table 5: FECs-119 Error Attribution

\begin{tabular}{ccc}
\hline Error Attribution & Number of Errors & \% of Total Errors \\
\hline English & 155 & 54 \\
\hline English \& Creole & 122 & 42 \\
\hline Creole & 6 & 2 \\
\hline Other & 7 & 2 \\
\hline Totals & 290 & 100 \\
\hline
\end{tabular}

Furthermore, as depicted by Table 5, the greatest number of errors within theFEC's-119 was attributed to the English, totaling 155 (54\%). The English and Creole category accounted for $122(42 \%)$ errors, while the Creole category accounted for $6(2 \%)$ errors; $7(2 \%)$ errors were attributed to other factors.

Table 6: Frequencies of Major Error Categories in all Compositions

\begin{tabular}{cccc}
\hline Error Categories & PECs & FEC's-017 & FECs-119 \\
\hline Lexicon & .011 & .015 & .01 \\
\hline Syntax & .011 & .007 & .008 \\
\hline Morphology \& Syntax & .009 & .008 & .006 \\
\hline Morphology & .006 & .004 & .002 \\
\hline
\end{tabular}

In terms of the frequencies of errors in all composition types, the lexicon accounted for the greatest number of errors within the composition corpus overall (see Table 6). The FECs-017 exhibited the highest frequency of .015, followed by the PECs with a frequency of .011 and the FECs-119 of .01. Syntax showed the second highest frequency rate of error for the PECs and the FECs119 at .011 and .008 respectively. However, for the FECs-017 the morphology 
and syntax category scored the second highest frequency of errors at .008 when compared to its syntax error frequency of .007. Morphology errors had the lowest frequencies in each composition sample, with the PEC's exhibiting a .006 rate, FECs-017 of .004 and FECs-119 of .002.

\section{LEXICON}

Table 7: Frequencies of Major Lexical Errors

\begin{tabular}{lccc}
\hline LEXICON & PECs & FECs-017 & FECs-119 \\
\hline Wrong Word, general & .006 & .004 & .003 \\
\hline Wrong Word, & .001 & .007 & .004 \\
\hline Pronoun reference & & & .001 \\
\hline $\begin{array}{l}\text { Wrong Word, Preposition/ } \\
\text { adverbial particle }\end{array}$ & .001 & .002 & \\
\hline
\end{tabular}

The major types of lexical errors involved the choice of words with in basic vocabulary, pronoun reference or preposition/adverbial particle (see Table 7). Errors in general reference occurred .006 of the time in the PECs sample, .004 for the FECs-017 and .003 for the FECs-119. The FECs overall exhibited a greater degree of pronoun reference errors with a rate of .007 for the 017 's and .004 for the 119's respectively.

Finding over 250 lexical errors in the composition corpus was quite surprising. This result alone, raises the question of Standard English mastery among many Bahamian students. Most of the lexical errors related to the choice and meanings of words, basic vocabulary, and general words in use, having the highest frequency in all the samples. Though student-composition topics addressed a number of contemporary social issues, the majority of these lexical errors pertained to general reference items.

PECs:

*(29) Repatriation of illegal immagration is a necessity.

*(35) Bahamian and foreigners alike urine and feaces in the bushes.

FECs-017

*(61) The problem is epidermal.

*(62) The problem with gangs in the schools could be solved by having a censor of things students enjoy doing.

Each underlined item above denotes a lexical error based on the SE target. Apparently, these highly visible lexical errors lend weight to the need for second dialect/language methodology in creole situations and bi-dialect contexts. Also based on these results, it is questionable whether lexical boundaries between BD and SE are readily distinguished. While the writers displayed a high degree of comprehensibility of English vocabulary and produced some 
relevant ideas and structures to address their assigned topics, many appear to lack productive competence requisite to expressing themselves adequately by employing SE structures.

\section{SYNTAX}

Table 8 below illustrates that the greatest degree of syntax errors concerned sentence structure rules, particularly those relating to co-ordination and subordination in the student writers trying to express their ideas clearly. For example, the omission of a conjunction occurred .005 of the time in the PECs, .002 in the FECs-017 and .003 in the FECs-119.

Table 8: Frequencies of Major Syntax Errors in all Compositions

\begin{tabular}{lccc}
\hline Syntax & PECs & FECs-017 & FECs-119 \\
\hline $\begin{array}{l}\text { Minus Conjunction } \\
(\text { Co-ord., Subord) }\end{array}$ & .005 & .002 & .003 \\
\hline Minus Article (A, An, The) & .001 & .001 & .001 \\
\hline Minus Word (General) & .001 & - & - \\
\hline Minus Subject & - & .001 & - \\
\hline $\begin{array}{l}\text { Minus Preposition/ } \\
\text { adverbial Particle }\end{array}$ & - & - & .001 \\
\hline
\end{tabular}

Thus, in the syntactic analysis, sentence construction was a critical area displaying linguistic inconsistencies and instability in usage for all levels. For instance, sentence subordination and co-ordination, as seen in the following examples, appeared to be problematic for a great majority of writers.

\section{PECs:}

*(10) With such fumies being continues and increasingly produced, by inhialing such fumes we are endangered.

*(11) Garbage in these vacant lots can cause serious problems to the environment, it is not healthy for us.

\section{MORPHO-SYNTAX}

The morpho-syntax data in Table 9 show that verbal constructions accounted for the highest frequency of morphology and syntax errors, particularly those relating to the third person point of view, both singular and plural. Moreover, verb forms appearing without the relevant -s morpheme on the third person singular form occurred .002 of the time in the PECs, .002 in the FECs-017 and .001 in the FECs-119. The verbal inflection for the third person singular form occurred with non-third person references .003 of the time in the PECs, .003 in the FECs-017 and .001 in the FECs-119. Also, it is noted that the verbal inflection for the simple past tense was omitted .003 of the times in the PECs and 
.001 in the FECs-119. This same -ed morpheme was oversupplied .001 of the time in the PECs and .001 in the FECs-017.

Table 9: Frequencies of Major Morpho-syntax Errors in Compositions

\begin{tabular}{lccc}
\hline MORPHO-SYNTAX & PECs & FECs-017 & FECs-119 \\
\hline VERB, MINUS -s 3 rd ps & .002 & .002 & .001 \\
VERB, MINUS -ed pt & .003 & - & .001 \\
\hline VERB, PLUS - s Non-3 rd ps & .003 & .003 & .001 \\
\hline VERB, PLUS -ed pt & .001 & .001 & - \\
\hline
\end{tabular}

Generally, in the morphology and syntax categories, the major recurrent feature for all the groups involved verbal constructions, particularly relating to subject/verb concord of the third person present and the use of the past tense -ed inflection. Since the majority of the morpho-syntactic errors in the PEC samples involved the omission or oversupply of grammatical inflections in verbal constructions, quite naturally, it is clear that grammatical concord and key SE structures have not been fully mastered by these student writers, either because of the nature of English rules or because of the influence from the creole grammar.

*(23) There is the problem of teenage pregnancy which have been around for some years.

*(24) We need to start from now while it is not that serious before it get to serious.

*(25) If we browse around and not try to be concern then when it come to us and we are all feeling the effect it will be to late.

\section{MORPHOLOGY}

The category of morphology scored the lowest number of errors in the composition corpus overall (see Table 10). The greatest number of morphological errors concerned the omission of the plural -s morpheme in all groups (see Table 12 below). This plural inflection was omitted .005 of the times in the PECs, .003 in the FECs-017 and .002 in the FECs-119. Also, the plural marker was oversupplied .001 of the time in the PECs. The possessive inflections were omitted .001 of the times in the PECs and .001 in the FECs-017 as well. Nevertheless, it is obvious from the analysis that the writers in question were grappling with SE inflections, particularly the ones involving grammatical number. For example, there were 121 cases of the omission of the plural $-\mathrm{s}$ on a noun, a frequency rate of .005 in the PECs sample. 


\begin{tabular}{lccc}
\hline MORPHOLOGY & PECs & FECs-017 & FECs-119 \\
\hline Minus Number, Noun & .005 & .003 & .002 \\
\hline Plus Number, Noun & .001 & - & - \\
\hline Minus Possessive, 'S/s' & .001 & .001 & - \\
\hline
\end{tabular}

Notably, many of the number marking errors occurred in rich contexts where some other element(s) in the sentences indicated plurality as opposed to singularity. These elements included numbers, indefinite pronouns such as some, many and all, for example:

*(1) Tree helps make the place green and produces oxygen.

*(2) This again can cause health problem for our citizen.

*(3) They are the reason for the so many asthma attack.

*(4) There are many disease that is going around.

These errors may be influenced by the generalized "plural," unmarked noun which is common in BEC. In this latter instance, a general noun is used in an utterance to indicate all members of a category. However, the omission of the plural inflection may also be attributed to the intrinsic nature of English. The findings from morpheme studies conducted by researchers concerning second language acquisition of English morphemes of L2 learners, provided sufficient evidence to support the belief that a natural ordered progression has been observed in the morpheme acquisition process of second language learners regardless of their L1 backgrounds (Larsen-Freeman and Long 1991: 88-92). Possibly, in a country like the Bahamas where SE may be regarded as a second dialect, if not a second language, linguistically, speakers may undergo similar stages of instability in their progression towards acquisition and mastery of the SE system. Therefore, in my study, the majority of these morphological errors were classified as attributable to both English and Creole influences.

In summary, the systematic occurrence of these non-standard features confirms for me the difficulty many student writers experience in having to use SE structures, that were not fully mastered linguistically. But this situation is not totally different from second language learners acquiring some variety of SE in addition to their L1 background. For example, with the acquisition of the English morpheme, degrees of instability are inevitable in a second language situation. After prolonged instruction in the target language and natural exposure to these inflections, it is possible for the second language learners to master the forms. However, "fossilization" is not uncommon, meaning that language learners may progress and achieve a certain level of control over the target structures, but then proceed no further (Larsen-Freeman \& Long 1991:60-61; Selinker 1992:33-34). 


\section{PEDAGOGICAL IMPLICATIONS}

Given the data generated in my study I reiterate that a great number of writing problems evidenced in the students' compositions stem from an L1 pedagogical bias. Until this bias is recognized and addressed appropriately, SE proficiency at critical levels of communication may continue to pose problems for many Bahamian students. However, an alternative methodology that can be considered is TESD. I believe that TESD would serve to motivate and encourage those who speak non-standard language varieties and who are not motivated to learn SE skills. Recognizing English as a second dialect/language in many Bahamian contexts values students' L1 background while at the same time using contrastive and comparative teaching techniques to highlight linguistic boundaries and linguistic differences between language systems. This methodology also highlights the complex and unique structures of the target language. Furthermore, TESD, being akin to L2-- second language methodology-- may facilitate the learners' development and language acquisition much better by integrating all language arts skills of reading, writing, listening and speaking in the target language. Essentially, communicative competence is its major goal, that is, using language appropriate to context. The language arts skills would be assigned varying degrees of instruction or intensity depending upon the social context of the instructional setting, the linguistic needs and backgrounds of the students, the qualification and preparation of the teachers, the available resources, and the purpose and objectives of the educational programme.

\section{CONCLUSION}

Although some West Indian publications and textbooks in use in the Bahamian schools have begun to address the needs of Caribbean students, formal language planning in The Bahamas, especially in key areas such as curriculum development and planning, materials preparation and instruction, has not seriously considered the issue of creole or dialect interference in SE performance. Indeed, such issues merit serious investigation concerning the connection between linguistic factors and educational policy and practice. Documenting the sociolinguistic needs of the school-going population can enhance language planning, curriculum design, and pedagogical policy. The pervasive linguistic insecurity many Bahamian students display in contexts requiring SE proficiency, as well as the performance on written SE examinations, are sufficient evidence for a critical need to researching the linguistic challenges of teaching and learning English in the Bahamas. Many of the "errors of grammar" recur systematically and seem to be rule-governed. Many "errors" seem to point to student writers at different stages of acquisition of SE rules. In this view, many errors that have been influenced by features from the first language seem to be strategies employed in the construction of the standard grammar. I believe the many of these student writers attempt to reconcile SE formal structures with their own vernacular language systems based upon the kinds of input they have received in their language development. Furthermore, I believe that some of the non-standard features in the composition corpus can be described as students' attempts to reconcile the irreconcilable linguistic differences between SE and vernacular grammars.

Finally, while the acquisition of a related second dialect is not the same as the 
acquisition of a second language, it is just as important for educators to recognize the linguistic context of a second dialect situation, and adopt relevant and more effective teaching techniques suited to the background and needs of the students. With this in view, the linguistic issues and problems that language teachers face in the classroom-- classrooms full of second dialect learners-would be addressed in the course of time; and student writers would progress in their grammar construction of composing SE texts, but with greater degrees of SE proficiency, and ultimately, greater academic success.

\section{NOTES}

1. Bahamianist: a linguist committed to the formal study of the languages of Bahamians, such as Bahamian English, Bahamian Dialect, Bahamian English Creole, or Bahamian Creole English, urban Bahamian, etc.

2. BD: Bahamian Dialect

\section{BEC: Bahamian English Creole}

4. Creole: In linguistics, this is a neutral linguistic term (any stigma attached, being social in nature, and not linguistic) that refers to a language system having evolved out of a multilingual contact situation. Sato captures its inherent nature in the following sentiment:

"Although a creole may be closely related to a language such as English, in its lexicon, it often diverges from that language substantially in all linguistic domains, that is, semantics, phonology, morphology, lexicon, and syntax" (Sato, 1989: 262).

Holm defines a creole language as a language system of mixed ancestry having arisen through diverse socio-cultural contact which developed in coastal, "colonized" regions among two or more disparate groups not having a common means of communication. The social history of the Caribbean and Atlantic regions were characteristic of such multilingual contact situations. It has been posited that the languages of European colonists and the languages of the transplanted West African peoples were the linguistic bedrock successive generations of African peoples used to "generate" creole languages (Holm, 1988: 6-9).

5. Dialect: In linguistics, this is a neutral linguistic term (any stigma attached, being social in nature, and not linguistic) that refers to a language variety with systematic distinct linguistic or grammatical features correlated with social or geographical factors; it may be deemed standard or non-standard (Major, 1993: 2-3).

6. $\boldsymbol{E L}$ : English Language

7. ESD: English as a Second Dialect

8. $\boldsymbol{E S / F L : ~ E n g l i s h ~ a s ~ a ~ S e c o n d ~ o r ~ F o r e i g n ~ L a n g u a g e ~}$

9. FECs: Final Examination Compositions collected from the English Department at C.O.B. 
10. Lexicon: In Linguistics, lexicon generally refers to the vocabulary, the stock of words in a language with their meanings and collocations.

11. Linguistics: the academic discipline concerned with the formal, scientific study of language: its description, structure, acquisition, development, and so on.

12. Linguistic interference/transfer: "a term used in sociolinguistics and foreign-language learning" to denote the errors a speaker generates in "one language as a result of contact with another language; also called negative transfer" (Crystal, 1991: 180). Language interference may also be defined as "the negative effect of new learning on the performance of previously learned behavior-- prior language acquisition-- with which it is inconsistent" (Selinker, 1992).

13. Morphology: In linguistics, morphology is the study of the internal structure of words and word formation.

14. Morpho-syntax: In linguistics, the study of the internal structure of words and word formation falls within the rubric of morphology; thus, morphosyntactic is a marriage of morphology + syntax.

15. PECs: Placement Examination Compositions collected from the English Department at C.O.B.

16. Pragmalinguistic: (an adjective blend of pragmatics + linguistics): "In modern linguistics, pragmatics can be applied to the study of language from the point of view of the users; also, principles and practices of conversational performance, including all aspects of language usage, understanding and appropriateness." Thus, pragmalinguistics can refer to the linguistic domain of pragmatics that studies pragmatic issues "from the viewpoint of the structural resources available in a language" (Crystal, 1991: 271).

\section{SE: Standard English}

18. Sociolinguistics: In Linguistics, sociolinguistics may be described as "a branch of linguistics which studies all aspects of the relationship between language and society" (Crystal, 1991: 319).

19. Syntax: In linguistics, syntax is the study of how phrases and clauses combine to form sentences; the study of the linguistic rules governing sentence structure and sentence formation.

20. TESD: Teaching English as a Second Dialect

21. TES/FL: Teaching English as a Second or Foreign Language

22. TESOL: Teaching English as a Second or Other Language 


\section{REFERENCES}

Bahamas National Task Force on Education. (1994). National task force on education: Final report. Nassau, Bahamas: Government Printing.

Carrington, L. (1983). The challenge of Caribbean language in the Canadian classroom. TESL TALK, 14 (4), 15-27.

Craig, D. (1980). Models for educational policy in Creole-speaking communities. In A. Valdman, \& A. Highfield (Eds.), Theoretical orientations in creole studies, (pp. 245-266). New York: Academic Press.

Crystal, D. (1991). A dictionary of linguistics and phonetics. Cambridge, Massachusetts: Blackwell Publishers.

Crystal, D. (1999). The future of English: A Welsh perspective. Paper presented at the 33rd Annual TESOL Convention, New York, N.Y.

Gray, B. Q. (1975). Dialect interference in writing: A tripartite analysis. Journal of Basic Writing, 1 (1), 14-22.

Halliday, A. (1994). Appropriate methodology and social context. Cambridge: Cambridge University Press.

Holm, J. (1988). Pidgins and creoles. Vol. 1: Theory and structure. Cambridge: Cambridge University Press.

Holm, J. and A. Shilling. (1982). Dictionary of Bahamian English. Cold Spring, NY: Lexik House Publishers.

Kachru, B. (1985). Institutionalized second-language varieties. In S. Greenbaum (Ed.), The English language today (pp 211-226). New York: Pergamon Press.

Kachru, B. (1992). The other tongue: English across cultures (2nd ed.). Urbana: University of Illinois Press.

Larsen-Freeman, D. \& Long, M. (1991). An introduction to second language acquisition research. New York: Longman, Inc.

Lawlor, A. (1988). Bahamian English or Bahamian Creole? A sociohistorical investigation. Paper presented at the Seventh Biennial Conference of the Society for Caribbean Linguistics. Nassau, Bahamas: The College of the Bahamas.

Major, M. (1993). Some non-standard features of college writing: Evidence for a second dialect approach to English language teaching in the Bahamas. Unpublished MA Thesis, Southern Illinois University at Carbondale, Illinois, U.S.A.

Nayar, P. B. (1997). ESL/EFL dichotomy today: Language politics or pragmatics? TESOL Quarterly, 31, 9-27. 
Pakir, A. (1999). Connecting with English in the context of internationalization. TESOL Quarterly, 33, 103-114.

Rampton, M.B. (1992). Scope for improvement in sociolinguistics? In D. Cameron (Ed.), Researching language: Issues of power and method (pp. 29-64). London: Rutledge.

Sato, C. (1989). A nonstandard approach to Standard English. Tesol Quarterly $23(2)$.

Selinker, L. (1992). Rediscovering interlanguage. New York: Longman, Inc.

Shannon, S. M. (1995). The hegemony of English: A case study of one bilingual classroom as site of resistance. Linguistics and Education, 7, 175-200.

Thomas-Ruzie, Maria. (1999). English and TESOL in times of change: As a second (or foreign, alternative, additional, international, native, standard, ...?) language (or dialect). Retrieved September 21, 2000, from http://www. tesol.org/isaffil/intsec/columns/199906-al.html.

Winer, L. (1982). An analysis of errors in the written English compositions of Trinidadian English Creole speakers. PhD Dissertation. University of the West Indies, Trinidad and Tobago. University Microfilms, Ann Arbor.

Winer, L. (1992). TESD. In T. McArthur (Ed.), The Oxford companion to the English language, (1033-1035). Oxford: Oxford University Press.

Winford, D. (1976). Teacher attitudes toward language varieties in a creole community. International Journal of the Sociology of Language, 8, 45-75.

Michelle Veronica Bain is a Bahamianist who has spent several years in English Studies at The College of The Bahamas teaching Linguistics and College English. Her main areas of scholarly work include research on Bahamian English Creole discourse, Bahamian Dialect, TESOL, Language Education in the Caribbean, and writing poetry. She has pursued graduate studies in Applied Linguistics, TESOL, and Language Education, at Southern Illinois University at Carbondale, Illinois, and at the University of Florida, Gainesville, Florida. 